\title{
Reproduction in female South American domestic camelids
}

\author{
J. B. Sumar \\ IVITA Research Institute, San Marcos University, Av. De Los Incas 1412, Cusco, Perú.
}

\begin{abstract}
Alpacas and llamas are induced ovulators. They show marked reproductive seasonality in the Andean region, but under Northern Hemisphere conditions of feeding and management, they are non-seasonal breeders. Puberty is attained when they reach $50 \%$ of adult body weight. When they are not exposed to a male, females show successive waves of follicular maturation and atresia. Growth, maintenance and regression of a follicle each require an average of 4 and 6 days in alpacas and llamas, respectively. After sterile mating, progesterone concentrations in blood were increased from day 5 , reached maximum concentrations on day $7-8$, and declined rapidly at $9-10$ days after mating. A fertile mating results in formation of a corpus luteum that remains functional throughout gestation. The duration of gestation is 340-346 days. Almost all fetuses were found to occupy the left uterine horn, even though ovulation occurs from both ovaries with equal frequency. Several methods of pregnancy diagnosis have been described. Mating is recommended within 15-20 days after parturition to obtain good fertility rates and one offspring per year. The factors that contribute to high rates of embryonic mortality are unknown. Reproductive technologies, such as AI, superovulation, embryo transfer and IVF, have not been used very extensively in these species but can be successfully applied.
\end{abstract}

\section{Introduction}

The family Camelidae comprises six species, and they are believed to have originated in western North America. Two of the species migrated through the Bering Strait into Asia, and four into South America where the llama (Lama glama) and the alpaca (Lama pacos) were domesticated 4000 to 5000 years ago and the guanaco (Lama guanicoe) and vicuna (Lama vicugna) are still found in the wild.

\section{Puberty}

Young female alpacas of $12-13$ months of age show behavioural oestrus similar to that of adult alpacas (Novoa et al., 1972); ovarian activity begins at 10 months of age, with the presence of follicles of $5 \mathrm{~mm}$ or more in diameter. In a study carried out in southern Perú using 280 yearling female alpacas, a relationship was found $(P<0.001)$ between body weight at mating and subsequent birth rates (Leyva and Sumar, 1981). For each kilogram increase in body weight, there was a $5 \%$ increase in birth rate, but when body weight exceeded $33 \mathrm{~kg}$, the percentage of non-pregnant females was relatively independent of body weight. In traditional Peruvian production systems, $50 \%$ or fewer of yearling alpacas reach $33 \mathrm{~kg}$ of body weight at mating time (1 year); therefore, breeding age is postponed until 2 years of age in alpacas and until after 3 years of age in llamas. It has also been shown that with better nutrition after weaning (7-8 months of age), almost $100 \%$ of yearling alpacas can reach $33 \mathrm{~kg}$ of body weight (Sumar, 1985).

\section{Seasonality}

Studies with alpacas and llamas in their natural habitat in the highlands of southern Perú (peasant community farms), where males and females are together all year, showed that the mating activities 
are seasonal, and last from December to March (summer months). These are the warmest months of the year, with sufficient rain and abundant green forage (San Martín et al, 1968). In addition, the wild species of camelids, the vicuna and guanaco, show this marked seasonality of reproduction (Sumar and Garcia1986).

Alternatively, when females are kept separately from males and copulation is allowed only once a month, both sexes are sexually active throughout the year. Ovulation and fertilization rates, together with embryo survival, were not affected significantly by the season of the year (FernándezBaca et al., 1972).

Continuous association of females and males inhibits the sexual activity of the male. Factors responsible for the onset and cessation of sexual activity under natural conditions are unknown. Environmental factors, in addition to visual and olfactory stimulation, could be of influence via the central nervous system (Fernández-Baca et al., 1972).

Observations in different zoological parks indicate that camelids, both domestic and wild, are year-round breeders (Schmidt, 1973). In North America, where llamas are kept under continuous good feeding conditions, llamas are considered non-seasonal breeders. An analysis of the birthing season for llamas in the Rocky Mountain area of the USA (LR Johnson, personal communication) indicated that births occurred all year, but most of them $(73 \%)$ occurred between June and November, i.e. during the warmest months.

\section{Pattern of Ovarian Events}

As copulation is a necessary prelude to ovulation in alpaca and llama, they have been classified as reflex or induced ovulators, rather than spontaneous ovulators (San Martín et al., 1968; England et al., 1969). Oestrus and ovulation do not occur in a repetitive, cyclic, and predictable fashion.

\section{Follicular development}

When they are not exposed to a male, female alpacas show long periods of sexual receptivity, and short periods of non-receptivity to the male that can last for $48 \mathrm{~h}$ (San Martin et al., 1968). These changes may be correlated with rhythmic increases and decreases in serum oestrogen concentrations that reflect successive waves of follicular maturation and atresia.

On the basis of ovarian laparoscopic examination of alpacas, it was found that growth, maintenance and regression of a follicle each required an average of 4 days (total 12 days; range 9-17 days) (Bravo and Sumar, 1989). Transrectal ultrasonography of llamas, in their natural habitat of Peru (Adams et al., 1990) showed that successive dominant follicles emerge at intervals of $19.8 \pm 0.7$ days in unmated and vasectomized-mated llamas and at intervals of $14.8 \pm 0.6$ days in pregnant llamas. Lactation was associated with an interwave interval that was shortened by $2.5 \pm 0.05$ days. Differences between species (alpaca versus llama), management conditions (poor natural grassland in Perú at $4300 \mathrm{~m}$ altitude versus intensive management and feeding conditions in USA at sea level), seasonal variation, method of examination, and number of animals evaluated may contribute to variation among studies. However, considerable variability between individuals has been detected regardless of reproductive status (parous versus nonparous). There is variability in both duration of sexual receptivity and regularity of its occurrence presumably because the follicular phase is not terminated by ovulation at a predetermined time in unmated females, and there is no luteal phase to delineate the timing of events after the end of oestrus.

\section{Ovulation}

The minimum time to ovulation in alpaca was estimated to be $26 \mathrm{~h}$ after natural mating and $24 \mathrm{~h}$ after treatment with hCG (San Martín et al., 1968). In receptive female alpacas allowed a single mating, $50 \%$ ovulated between 26 and $30 \mathrm{~h}, 24 \%$ ovulated between 30 and $72 \mathrm{~h}$, and $26 \%$ failed to ovulate after mating (Sumar, 1991). Forty per cent of the animals that failed to ovulate were yearlings 
and $15 \%$ were adults. Single service by an intact or vasectomized male resulted in ovulation in $77-82 \%$ of alpacas, and an increase in the number of services by intact males to three within a period of $24 \mathrm{~h}$ did not significantly affect ovulation rate (Fernández-Baca et al., 1970c). Ovulation was also induced successfully after treatment with $1 \mathrm{mg} \mathrm{LH}$, and a dose of $4-8 \mu \mathrm{g}$ of GnRH was also necessary to provide an adequate stimulus for ovulation (Sumar, 1985). Use of an ultrasonographic technique in llamas allowed the detection of ovulation, on average, 2 days (range 1 to 3 days) after a single mating (Adams et al., 1989, 1990).

A significant increase in serum LH concentration was observed $15 \mathrm{~min}$ after the onset of copulation, and the preovulatory peak surge of LH occurred at $2 \mathrm{~h}$; concentrations reached basal values by $7 \mathrm{~h}$ after copulation (Bravo et al., 1990). A second release of LH was not detected after a second copulatory period within $24 \mathrm{~h}$ of the first release. The LH surge observed subsequent to copulation is consistent with the contention that alpaca and llama are induced ovulators.

There are some indications that females can ovulate in the absence of coital stimulation or exogenous hormones. This is particularly evident when the female is initially isolated from, and then reintroduced to, a male. The rate of spontaneous ovulation was reported to be approximately 5-10\% in alpacas (Femández-Baca et al., 1970a; Sumar and García, 1986) and 9-15\% in llamas (Adams et al., 1989, 1990; England et al, 1969).

In addition, it has been reported that deposition of semen in the vagina of the bactrian camel will induce ovulation (Chen et al., 1985), which has led to the proposition that there may be an 'ovulation inducing factor' (OIF) in camel and bull semen. Because of the close phylogenetic relationship between Old and New World Camelidae, it was considered likely that similar effects would be observed in alpacas and llamas. Similarly, ovulation in alpacas and llamas can be induced by deposition of alpaca, llama or bull semen in receptive alpacas or llamas (Sumar, 1994). In the case of camels, Chinese investigators proposed the presence of a GnRH-like substance in camel and bull semen. Conversely, Paolicchi et al. (1996) found that alpaca semen contains a factor or factors, other than GnRH, that contributes to the LH secretion mechanism in this species.

\section{Function of the corpus luteum}

The function of the corpus luteum after sterile and fertile mating has been studied in domestic camelids. The concentration of progesterone in blood of female alpacas and llamas that were mated with infertile (vasectomized) males was increased from day 5 , reached maximum concentrations of 10-20 nmol $\mathrm{H}^{-1}$ on day 7-8, and declined rapidly at 9-10 days after mating in association with repeated surge releases of prostaglandin $\mathrm{F}_{2 a}$ (Sumar et al., 1988). Oestradiol concentrations were > $100-200 \mathrm{pmol}^{-1}$ during oestrus when the animals were mated. A temporary increase in oestradiol was detected that was related to the rise in progesterone concentrations in the early luteal phase. Otherwise, oestradiol concentrations remained low, 20-40 $\mathrm{pmol} \mathrm{l}^{-1}$, during the luteal phase, and increased in most animals to $40-60$ pmol $^{-1}$ after luteolysis. During the 3-4 days after coitus, when the corpus luteum is forming and progesterone concentrations are low, most females remain receptive to males. Plasma concentrations of progesterone in females that displayed sexual receptivity at this time were between 0.06 and $0.28 \mathrm{ng} \mathrm{ml}^{-1}$ (Sumar et al, 1993). In ultrasonography studies in llamas, the corpus luteum was first detected on day $3.1 \pm 0.2$ (day $0=$ ovulation) in females mated to vasectomized males and reached maximum diameter $(12.8 \pm 0.3 \mathrm{~mm})$ on mean day $5.9 \pm 0.3$ (Adams et al., 1991). Luteal diameter and plasma concentration of progesterone were highly correlated $(r=0.83, P<0.0001)$. A prolonged luteal phase was not observed in any sterile-mated (non-pregnant) alpaca or llama.

A fertile mating results in formation of a corpus luteum that remains functional throughout gestation. Luteal diameter was monitored by transrectal ultrasonography and plasma progesterone concentrations were determined in 68 pregnant llamas (Adams et al., 1991). The corpus luteum was detected on mean day $3.1 \pm 0.2$, and reached maximum diameter $(16 \mathrm{~mm}$ ) on mean day $21.4 \pm 1.2$ (day $0=$ day of ovulation). There was a decrease in mean plasma progesterone concentration between days 8 and 10, as well as a transient decrease in luteal diameter during this period. A similar decrease in progesterone between days 8 and 11 has been reported in alpacas (Sumar et al., 1993). The 
transient fall in progesterone is coincident with the initiation of uterine-induced luteal regression in non-pregnant animals. It has been suggested that the rescue and resurgence of the corpus luteum between 8 and 10 days after mating represents the luteal response to pregnancy (maternal recognition). Plasma concentrations of progesterone remained high until about 2 weeks before parturition (Leon et al., 1990). Thereafter progesterone concentrations began to decline and decreased markedly during the final $24 \mathrm{~h}$ before parturition. In addition, progesterone concentrations during sterile and fertile mating have been measured in the milk of alpacas and llamas (Sumar, 1991).

\section{Sexual Receptivity and Mating Behaviour}

The receptive female will assume the prone position (ventral recumbence) after a short period of pursuit by a male, or she may approach a male that is copulating with another female and adopt the prone position (San Martin et al., 1968; England., 1971). Some receptive females may occasionally display mounting behaviour with other females of the herd, although such behaviour is much less common than in cattle. A non-receptive female runs away from and spits at the male to show rejection. During the very short courting phase and during mating, the males make blowing, grunting, laryngeal-nasal sounds. Copulation takes place in a recumbent position, with the male mounted above and just behind the female (England et al., 1971). The female assumes a very passive attitude during copulation, and in some instances when copulation is prolonged, will appear to tire and may change positions so that she is lying on her side. Compared with other domestic species, coitus is remarkably prolonged in camelids (10-50 min) (Sumar, 1985).

\section{Pregnancy}

\section{Duration of gestation}

The duration of gestation in alpacas of the Huacaya and Suri breeds was reported to be 341 and 345 days, respectively (San Martin et al., 1968). In llamas, the duration of gestation was $346 \pm 8$ days $(327-357)$, and neither parity nor sex of the cria was found to influence the duration of gestation (Sumar, 1985).

\section{Site of pregnancy and role of the corpus luteum}

Almost all alpaca and llama fetuses were found to occupy the left uterine horn (based on position of the conceptus and site of umbilical attachment), even though ovulation occurs from both ovaries with equal frequency (Table 1) (Fernández-Baca et al., 1973; Sumar, 1985). Thus embryos originating in the right side, migrate to the left horn for attachment. The reason for the right-to-left migration, which is apparently unique to Camelidae is not well known. There may be a differential luteolytic effect between the left versus right uterine horns. The right horn effects luteolysis via a local pathway, whereas the left horn effects luteolysis via both systemic and local pathways (Fernández-Baca et al., 1979), which may be implicated in the reduction of twin pregnancies to single pregnancies (Sumar, 1991, 1996). The role of the corpus luteum during pregnancy in llama and alpaca has been studied by Sumar (1983), and results indicate that the corpus luteum is necessary for maintenance of pregnancy during the entire gestation period in both species.

\section{Pregnanoy diagnosis}

Several methods of pregnancy diagnosis have been described for llamas and alpacas.

Sexual behaviour. Females that showed behavioural receptivity to teaser alpaca males (vasectomized) 20 or more days after a previous service were found not to be pregnant (Fernandez- 
Table 1. Location of corpora lutea (CL) and embryos in alpacas and llamas

\begin{tabular}{lcccccc}
\hline Species & $\begin{array}{c}\text { Number of } \\
\text { animals }\end{array}$ & $\begin{array}{c}\text { Number with CL } \\
\text { in right ovary }(\%)\end{array}$ & $\begin{array}{c}\text { Number with CL, } \\
\text { in left ovary (\%) }\end{array}$ & $\begin{array}{l}\text { Number with CL } \\
\text { in both ovaries (\%) }\end{array}$ & $\begin{array}{c}\text { Right horn } \\
\text { pregnancy (\%) }\end{array}$ & $\begin{array}{c}\text { Left horn } \\
\text { pregnancy }(\%)\end{array}$ \\
\hline $\begin{array}{l}\text { Alpaca } \\
\text { Llama }\end{array}$ & 928 & $472(50.9)$ & $440(47.4)$ & $16(1.7)$ & $15(1.6)$ & $913(98.4)$ \\
\hline
\end{tabular}

Data from Fernández-Baca et al. (1973); Sumar (1985); Sumar (1986).

Baca et al, 1970a, b). However, not all females that rejected the male were found to be pregnant. In another study, the accuracy of pregnancy diagnosis was $84 \%$ and $95 \%$ in the alpaca and llama, respectively, within 70-125 days of gestation, and this is comparable to the accuracy obtained in sheep (Alarcón et al., 1990).

External palpation. This method is still used in the traditional breeding system in southern Perú, with an accuracy of about $80 \%$. Pregnancy diagnosis is done by external palpation or ballotement at approximately 8 months of gestation (Sumar, 1985).

Rectal palpation. In alpacas rectal palpation is possible as early as 30 days of gestation, but this method is limited because of the small pelvis and fat deposition in the pelvic inlet, particularly in yearling animals (Alarcón et al., 1990). Seventy per cent of yearlings and $90 \%$ of adult alpacas can be palpated rectally. In llamas, almost $100 \%$ can be palpated, given adequate restraint, lubrication and a skilled veterinarian, with a glove size no greater than 7 . The accuracy of pregnancy diagnosis by rectal palpation at 2 months after mating was 100\% in alpacas and llamas (Alarcón et al., 1990).

Circulating hormones. Progesterone concentrations can be determined during gestation by standard analytical methods such as radioimmunoassay and enzyme immunoassay. Alpacas or llamas that failed to ovulate, as well as those that failed to conceive, showed basal concentrations of progesterone on day 12 and 30 after mating, whereas animals were considered pregnant when progesterone concentrations were $>1.8 \mathrm{ng} \mathrm{ml}^{-1}$. The occurrence of false positive predictions, related to high blood progesterone concentrations, is probably due to early embryonic loss (Sumar et al, 1993).

Oestrone sulfate concentrations varied between 0.02 and $1.2 \mathrm{nmol} \mathrm{l}^{-1}(0.26 \pm 1.9)$ from mating until about days 246 and 262 of gestation in alpacas and llamas (Sumar et al., 1990). Thereafter, oestrone sulfate concentrations increased very rapidly, and the highest concentrations were observed at 3 days before parturition at $19.82 \pm 5.74$ and $15.6 \pm 2.7 \mathrm{nmol} \mathrm{l}^{-1}$ in alpacas and llamas, respectively. A sharp decrease of oestrone sulphate occurred on day 1 postpartum in both species, reaching basal concentrations at 6-7 days postpartum. Therefore oestrone sulfate can be used for diagnosis of advanced stages of pregnancy and for the well being of the fetus.

Milk progesterone. Differences in concentrations of progesterone in milk can be observed between lactating non-pregnant and pregnant alpacas at 12 days after mating and may provide an early pregnancy test (Sumar, 1991; Sumar et al,, 1993).

Fecal progestagens. Schwarzenberger ef al. (1995) reported that concentrations of progestagens in faeces can be a non-invasive method for investigating reproductive events in wild camelids such as the vicunas.

Ultrasound techniques. Ultrasound techniques that were developed specifically for sheep have been used in alpacas and llamas (Alarcón et al., 1990). In alpacas, the highest accuracy $(92 \%)$ was recorded at a mean fetal age of 80 days. In llamas, $100 \%$ accuracy was obtained at 75 days of gestation. External 
ultrasound diagnosis of pregnancy can be performed with a $3 \mathrm{MHz}$ probe from 50 days until term, by applying the probe to the bare-skinned area just medial to the stifle (Johnson, 1989). Recent reports showed that transrectal ultrasonography is well suited to the study of the fetal development from 15 days after mating (Adams et al., 1989, 1990).

\section{Parturition}

Unassisted labour in alpacas at $4250 \mathrm{~m}$ above sea level in Perú lasts a mean of $203 \pm 129$ min for primiparous females and $193 \pm 122 \mathrm{~min}$ for multiparous females (Sumar, 1985). In llamas, a mean of $176 \mathrm{~min}$ was reported for the three different stages of labour (Sumar, 1991). Camelids do not lick their offspring at birth, nor do they abandon the cria, even if they are of extremely poor nutritional status. More than $90 \%$ of births in alpacas and llamas occur between 07.00 and $13.00 \mathrm{~h}$. This adaptation gives the cria the best chance to get warm and dry before the coldness of the night, where even in the summer, freezing temperatures are common at altitudes higher than $4000 \mathrm{~m}$ (Sumar, 1985).

\section{Puerperium}

Up to day 4 after parturition the female alpaca is submissive and will allow herself to be mounted by a male (Sumar et al., 1972). However, luteal regression, follicular growth and uterine involution are not complete, and the female will not ovulate or become pregnant from such early matings. Occasionally fertilization occurs subsequent to mating at 5 days post-partum. By day 10 post-partum the follicles are $8-10 \mathrm{~mm}$ in diameter, the corpus luteum has regressed considerably, and the uterus has involuted substantially (weighing only a fifth of its weight $24 \mathrm{~h}$ after birth). Mating in alpaca is recommended within 15-20 days after the female gives birth to obtain good fertility rates and one offspring per year (Sumar et al., 1972).

\section{Embryonic and fetal loss}

In an early study, more that $80 \%$ of the ova recovered 3 days after mating were in the process of dividing, and only $50 \%$ of the fertilized ova survived for more that 30 days of gestation in alpacas (Fernandez-Baca et al., 1970a). The factors that are responsible for this high rate of embryonic mortality are unknown, but nutritional constraints, hormonal imbalances, and chromosomal aberrations may be principal aetiologies. These studies were conducted in alpacas living in their natural habitat, affected by a harsh natural environment, deteriorating feed supply and the presence of infectious and parasitic diseases. Measurement of mean concentrations of plasma progesterone (Table 2) in female alpacas and llamas that were mated with fertile males indicate that progesterone concentration on day 8 after service are higher in pregnant than in non-pregnant animals $(P<0.05)$ (Sumar et al., 1993). Whether these levels are higher in pregnant animals, owing to the presence of a live embryo, or lower in non-pregnant animals, because of the incapability of the corpus luteum to secrete progesterone, is still unknown.

\section{Twinning}

Multiple ovulations occur in 3-10\% of alpacas after natural mating and in 9-20\% after treatment with gonadotrophins. However, the birth of twins is very rare. Cases of twin pregnancies in alpacas, seen in the early stages of gestation ( $<40$ days of gestation) are not uncommon (Sumar, 1986). It is believed that there is a reduction in the number of embryos and that probably a single embryo continues to develop. Twin births in llamas may be somewhat more common than in alpacas, and a few cases of twin births in llamas have been reported in the USA (Fowler, 1989). Nearly all alpaca and llama twins are of the fraternal or dizygotic type. Monozygotic twin pregnancies are rare. Similar to the mare, in $95 \%$ of alpacas or llamas with twin ovulations, one or both ova or embryos are 
Table 2. Mean plasma progesterone concentrations (nmol 1-1) in female alpacas and llamas mated with fertile males

\begin{tabular}{lccccc}
\hline & \multicolumn{2}{c}{ Alpacas $(n=12)$} & & \multicolumn{2}{c}{ Llamas $(n=10)$} \\
\cline { 2 - 3 } Day after mating & Pregnant & Non-pregnant & & Pregnant & Non-pregnant \\
\hline 1 & 0.32 & 0.38 & & 0.53 & 0.45 \\
5 & 2.46 & 1.46 & & 1.93 & 1.38 \\
8 & 18.50 & 12.03 & & 16.41 & 10.90 \\
9 & 16.34 & 3.20 & & 17.81 & 14.10 \\
10 & 13.70 & 0.76 & & 20.70 & 6.90 \\
11 & 12.84 & - & & 25.13 & 2.90 \\
12 & 16.00 & - & & 23.28 & 0.28 \\
\hline
\end{tabular}

Values are means. Reproduced with permission from Sumar et al (1993).

lost early in the gestation period. In twin pregnancies proceeding to term, one is well at birth and the other is frequently small or very weak.

\section{Artificial insemination}

A number of studies have examined the feasibility of artificial insemination in alpacas and llamas, involving deposition of fresh semen into the corpus uteri or into the right uterine horn with the use of the recto-palpation method (Fernández-Baca and Novoa, 1968). Inter-species crosses have also been tested between alpaca and vicuña (the F1 is known as paco-vicuña), and between llama and vicuña (llama-vicuna). In one study conducted to determine the most appropriate time for insemination, the highest proportion of fertilized ova occurred $35-45 \mathrm{~h}$ after induction of ovulation (Calderón et al., 1968). The fertility rates were higher when vasectomized males were used to induce ovulation than when hCG was used.

Further studies were conducted using vicuña semen (V) and paco-vicuña semen with female alpacas (A) and llamas (Ll) (Leyva et al., 1977). The birth rate obtained when vicuña was crossed with llama was $16.7 \%(1 / 2 \mathrm{~V}-1 / 2 \mathrm{~A})$, and when vicuña was crossed with alpaca was $22 \%(1 / 2 \mathrm{~V}-1 / 2 \mathrm{~A})$. Crossing the paco-vicuña with llama produced a $60 \%$ birth rate $(1 / 2 \mathrm{~A}-1 / 2 \mathrm{~V}-1 / 2 \mathrm{Ll})$, and $31.1 \%$ birth rate for pacovicuña semen with alpaca $(3 / 4 \mathrm{~A}-1 / 2 \mathrm{~V})$. Domestic and wild camelids offer advantages compared with other animal species in the potential use of artificial insemination because females are in continuous oestrus during the breeding season, ovulation can be induced with vasectomized males, and semen can be inseminated into the uterus (Calderón et al., 1968).

\section{Embryo Transfer}

Pugh and Montes (1994) and Del Campo (1997) used advanced reproductive technologies, such as superovulation, cryopreservation of embryos, embryo transfer, in vitro maturation, and in vitro fertilization of ocytes, in domestic South American camelids.

\section{Superovulation of donors}

The first attempt to superovulate three alpacas was in 1968 (Sumar, 1985) with the use of 1200 iu PMSG given subcutaneously (Gestyl, Organon) as three consecutive daily doses of 400 iu. At 24 h after the last PMSG injection, the females were given an intravenous injection of hCG (750 iu; Pregnyl, Organon), and the female was mated immediately with a fertile male. At 72 h after mating, the females were sedated and three embryos from each female were collected surgically, Follicular 
growth and number of corpora lutea were not recorded. More recent studies in alpacas and llamas reported successful superstimulation with eCG or pituitary FSH in the presence of an induced corpus luteum or a progestagen treatment with ovulation being induced by GnRH, hCG or mating (Bourke et al., 1991, 1992, 1995a; Del Campo et al., 1995). Co-ordination of ovarian superstimulation with follicle development was achieved with eCG administered when follicles were $3 \mathrm{~mm}$ in diameter and after a complete follicle wave had occurred as determined by ultrasonography (Bravo et al., 1995). ECG doses of 500 and 1000 iu are appropriate for inducing follicular growth in llamas. In contrast a dose of 2000 iu eCG caused hyperstimulation with an increasing incidence of cystic follicles. As evident in other species, there was wide variation in individual animal responses to eCG and embryo recovery rate was very low (Del Campo et al., 1995).

\section{Recovery procedures}

Embryos from donor alpacas have been collected either surgically or non-surgically. Collection of zygotes from the oviduct of alpacas by abdominal laparotomy has been reported (Sumar, 1986). Zygotes were flushed from the oviduct to the uterus and collected through an incision made in the uterine horn. The presence of a valve in the utero-tubal junction precludes flushing from the uterus into the oviduct. The recovery rate in single ovulating alpacas was about $80 \%$ and no data were reported for superovulated animals.

Non-surgical techniques used in other domestic animals for the recovery of embryos have been adapted successfully for use in llamas and alpacas (Wiepz and Chapman, 1985; Correa et al., 1992; Bourke et al., 1992, 1995a; Del Campo, 1997). Embryo recovery is usually attempted 7 days after mating or GnRH injection. It is important to note that alpaca or llama embryos enter the uterus at about day 4 or 5 (day $0=$ day of mating). To date, embryo recovery rate has not been higher than $50 \%$ (Del Campo et al., 1995).

Ultrasound-guided transvaginal follicle aspiration has been used to collect oocytes in llamas with a $64 \%$ collection rate (Brogliatti et al., 1966).

\section{Recipient management and embryo transfer}

Recipient females were synchronized with a single injection of hCG in receptive alpaca females or GnRH at the time of mating the female llama donor (Bourke et al., 1995b; Sumar; 1986, 1996). Embryos were loaded into an inseminating pipette and transferred surgically to the left uterine horn.

A nonsurgical transfer approach was made transcervically via a Cassou-gun, into the tip of the uterine horn ipsilateral to the corpus luteum. The embryo was loaded into a $0.25 \mathrm{mI}$ straw (Bourke et al., 1995b). It is recommended that embryos always be placed into the left uterine horn since embryos in the left uterine horn migrate to the right uterine horn and this may contribute to embryo mortality (Fernández-Baca et al., 1979).

Over the past 26 years, 11 crias have been born throughout the world as a result of embryo transfer techniques (Del Campo, 1997). Researchers from Perú reported a successful surgical embryo transfer and live birth of one alpaca and three late abortions (Sumar, 1985, 1986). The first llama born by a non-surgical collection and transfer technique was in the USA (Weipz and Chapman, 1985). Later, six live crias were born in the United Kingdom between 1992 and 1995 (Bourke et al, 1995b). In Chile, the birth of one llama cria after two non-surgical embryo transfers was reported in 1994 (Del Campo, 1997).

\section{IVF technology}

Llama oocytes were collected either by mincing the ovary with a razor blade or by aspiration from ovarian follicles 2-11 mm in diameter (Del Campo et al., 1992). Del Campo and coworkers (1994) conducted the first in vitro maturation of oocytes, in vitro fertilization with epididymal spermatozoa and in vitro co-culture of embryos with oviductal cells. From a large number of oocytes 
examined for signs of fertilization, $29.2 \%$ were penetrated by spermatozoa, $57.1 \%$ of the penetrated oocytes had male and female pronuclei. There is also evidence to suggest that a longer period is necessary for oocyte maturation in alpacas and llamas than in other species such as cows ( $36 \mathrm{~h}$ versus $24 \mathrm{~h}$ ).

According to Del Campo et al. (1995), llama embryo-trophoblast expansion ranged from a mean of $1.2 \mathrm{~mm}$ in diameter on day $6.5-7.5$ to $83 \mathrm{~mm}$ on day $13-14$. This accelerated rate of embryo development may be related to the early maternal recognition of pregnancy in these species (Adams. et al., 1991).

\section{Conclusions}

The results obtained to date indicate that domestic South American camelids have particular and unique reproductive characteristics, but there is a need for more detailed investigation and careful observation. Maximizing reproductive performance is highly desirable in monotocous species, such as alpacas and llamas, that have a long pregnancy.

The ovarian follicular dynamics, hormone secretion and ovulation have not been very well established. Determining the follicular wave stage and follicular maturation will be a great advance in reproductive physiology of these species, and will help the reproductive management of mating or insemination. These studies require the development of advanced ultrasonographic techniques or rapid laboratory methods to measure the hormonal status of the animals. As alpacas and llamas are induced or reflex ovulators, studies of the different oestrogenic hormones and rapid quantification would be particularly helpful.

In addition, for embryo transfer, studies on the control of the follicular wave and on obtaining multiple ovulations, without damaging the ovaries and other organs, are urgently needed. Superovulation and embryo transfer in South American camelids are still in their early stages, and better results will be obtained, when appropriate techniques for induced ovulators that do not have an oestrous cycle, but do have follicular waves, are available.

\section{References}

Adams GP, Griffin PG and Ginther OJ (1989) In situ morphologic dynamic of ovaries, uterus and cervix in llamas Biology of Reproduction $41551-558$

Adams GP, Sumar J and Ginther OJ (1990) Effects of lactational and reproductive status on ovarian follicular waves in llamas (Lama glama) Joumal of Reproduction and Fertility 90 535-545

Adams GP, Sumar J and Ginther OJ (1991) Form and function of the corpus luteum in llamas Aniual Reproduction Science 24 $127-138$

Alarcón V, Sumar J, Riera GS and Foote WC (1990) Comparison of three methods of pregnancy diagnosis in alpacas and Ilamas Theriogenology 34 1119-1127

Bourke DA, Adam CL and Kyle CE (1991) Successful pregnancy following non-surgical embryo transfer in llamas Veterinary Record 12868

Bourke DA, Adam CL, Kyle CE, McEvoy TG and Young P (1992) Ovulation, superovulation and embryo recovery in llamas. In Proceedings of the 12 th International Congress on Animal Reproduction 57 193-195

Bourke DA, Kyle CE, McEvoy TG, Young P and Adam CL (1995a) Superovulatory responses to eCG in Ilamas (Lama glama) Theriogenology 44 255-268

Bourke DA, Kyle CE, McEvoy TG, Young P and Adam CL (1995b) Recipient synchronization and embryo transfer in South American camelids Theriogenology 43 171-177

Bravo PW and Sumar J (1989) Laparoscopic examination of the ovarian activity in alpaca Aitinal Reproduction Science 21 271-281

Bravo PW, Fowler ME, Stabenfeldt GH and Lasley B (1990) Endocrine responses in the llama to copulation Theriogenology 33 891-899

Bravo PW, Tsutsui T and Lasley BL. (1995) Dose response te equine chorionic gonadotropins and subsequent ovulation in llamas Small Ruminant Researclt 18 157-163

Brogliatti GM, Palasz AT and Adams GP (1996) Ultrasoundguided transvaginal follicle aspiration and vocyte collection in llamas (Lmia glama) Theriogenology 45249

Calderón W, Sumar J and Franco E (1968) Avances en la inseminación artificial de las alpacas (Lama pacos) Revista de la Facultad de Medicina Veterinarín Universidnd Nacional Mayor de San Marcos 22 19-35

Chen BX, Yuen ZX and Pan GW (1985) Semen-induced ovulation in the Bactrian camel (Camelus bactrianus) Journal of Reproduction and Fertility 74335-339

Correa JE, Gatica R, Ratto M, Ladrix R and Schulex C (1992) Studies on non-surgical recovery of embryos from South American camelids. In Proceedings of the 12th Hternational Congress on Animal Reproduction, The Hague, 788-790

Del Campo MR (1997) Reproductive technologies in South American camelids. In Current Therepy in Large Animal Theriogenology Ed. R. S. Youngquist. W. B. Saunders Company, Philadelphia 
Del Campo MR, Donoso MX, Del Campo CH, Rojo R, Barros C, Parrish JJ and Mapletoft RJ (1992) In vitro maturation of llama (Lama glama) oocytes. In Proceedings of the 12th International Congress on Animal Reproduction The Hague, Vol. $1324-326$

Del Campo MR, Donoso MX, Del Campo CH, Berland M and Mapletoft RJ (1994) In vitro fertilization and development of Llama (Lama glama) oocytes using epididymal spermatozoa and oviductal cell co-culture Theriogenology 411219-1229

Del Campo MR, Del Campo CH, Adams GP and Mapletoft RJ (1995) The application of new reproductive technologies to South American camelids Theriogenology 43 21-30

England BG, Foote WC, Matthews AG, Cardozo SG and Riera S (1969) Ovulation and corpus luteum function in the llama (Lama glama) Journal of Endocrinology 45 505-513

England BG, Foote WC, Cardozo AG, Matthews DH and Riera S (1971) Oestrous and mating behaviour in the llama (Lama glana) Animal Behavior $19722-726$

Fernández-Baca $S$ and Novoa $C$ (1968) Primer ensayo de inseminación artificial de alpacas (Lama pacos) con semen de vicuña (Vicugna vicugna). Revista de la Facultad de Medicina Velerinaria, Universidad Nacional Mayor de San Marcos 22 9-18

Fernández-Baca S, Hansel $W$ and Novoa C (1970a) Embryonic mortality in the alpaca Biology of Reproduction 3 243-251

Fernández-Baca S, Hansel W and Novoa C (1970b) Corpus luteum function in the alpaca Biology of Reproduction 3252-261

Fernández-Baca S, Madden DHL and Novoa C (1970c) Effects of different mating stimuli on induction of ovulation in the alpaca Journal of Reproduction and Fertility 22 261-267

Fernández-Baca S, Sumar J and Novoa C (1972) Comportamiento de la alpaca macho frente a la renovación de las hembras Revista de Investigaciones Pecuarias (IVITA) Universidad Nacional Mayor de San Marcos 1 115-128

Fernández-Baca S, Sumar J, Novoa C and Leyva V (1973) Relación entre la ubicación del cuerpo luteo y la localización del embrión en la alpaca Revista de Investigaciones Pecuarias (IVITA) Universidad Nacional Mayor de San Marcos 2 131-135

Fernández-Baca S, Hansel W, Saatman R, Sumar J and Novoa C (1979) Differential luteolytic effect on right and left uterine horns in the alpaca Biology of Reproduction 20 586-595

Fowler ME (1989) Medicine and Surgery of South American Camelids. Llama, Alpaca, Vicuña, Guannco. Iowa University Press, Ames

Johnson LW (1989) Llama reproduction. In The Veterinary Clinics of North America. Food Animal Practice, Llama Medicine, Vol, 5 (1) W. B. Saunders Company, Philadelphia

Leon JB, Smith BB, Timm KI and Le Cren G (1990) Endocrine changes during pregnancy, parturition and the early postpartum period in the llama (Lama glama) Joumal of Reproduction and Fertility 88 503-511

Leyva V and Sumar J (1981) Evaluación del peso corporal al empadre sobre la capacidad reproductiva de hembras alpaca de un año de edad. Meniorias de la IV Convención Internacional sobre Camélidos Sudamericanos, Corporación Nacional e Instituto de la Patagonia, Chile, Punta Arenas (Abstract 1)

Leyva V, Franco J and Sumar J (1977) Inseminación Artificial en Camélidos Sudamericanos. In Memorias de la I Reunión Asociacion Peruana de Producción Animal (APPA), Lima, Perú.
Novoa C, Fernández-Baca S, Sumar J and Leyva V (1972) Pubertad en la alpaca. Revista de lnvestigaciones Pecuarias (IVITA) Universidat Nacional Mayor de San Marcos $129-35$

Paolicchi F, Urquieta B, Del Valle L and Busłos-Obregón E (1996) Actividad Biológica del Plasma Seminal de Alpaca: Estimulo para la Producción de LH por Células gonadotropas Revista Argentina de Produccion Animal 16 351-356

Pugh DG and Montes AJ (1994) Advanced reproductive technologies in South American camelids. In Veterinary Clinics of North America: Food Animal Practice. Update on Llama Medicine Vol. 10 (2). W. B. Saunders Company, Philadelphia

San Martín M, Copaira M, Zún̄iga J, Rodriguez R, Bustinza G and Acosta L (1968) Aspects of reproduction in the alpaca Journal of Reproduction and Fertility 16 395-399

Schmidt CR (1973) Breeding season and notes on some other aspects of reproduction in captive camelids International Zoo Yearbook 13 387-390

Schwarzenberger F, Speckbacher G and Bamberg E (1995) Plasma and fecal progestagen evaluations during and after the breeding season of the female vicuna (Vicugna vicugina) Theriogenology 43 625-634

Sumar J (1983) Removal of the ovaries or ablation of the corpus luteum and its effect on the maintenance of gestation in the alpaca and llama Acta Veterinaria Scandinavica Supplementum 83 133-141

Sumar J (1985) Reproductive physiology in South American camelids. In Genetics of Reproduction in Sheep Eds RB Land and DW Robinson. Butterworths, London.

Sumar J (1991) Contribution of the radioimmunoassay technique to knowledge of the reproductive physiology of South American Camelids. In Isotope and Related Techniques in Animal Production and Health PP 353-379 FAO/IAEA, Vienna

Sumar J (1994) Effect of various ovulation induction stimuli in alpacas and llamas Journal of Arid Enviromments 26 39-45

Sumar J (1996) Reproduction in llamas and alpacas Animn Reproduction Science $42405-415$

Sumar J and Garcia M (1986) Fisiologia de la reproducción de la alpaca. In Procedings of the Symposium on Nuclear and Reiated Techniques in Animal Production and Health pp 169-177 IAEA, Vienna

Sumar J, Novoa C and Fernández-Baca S (1972) Fisiología reproductiva post-parto en la alpaca Revista de Investigaciones Pecuarias (IVITA) Unizersidad Nacional Mayor de San Marcos 1 21-27

Sumar $\mathrm{J}$, Fredriksson $\mathrm{G}$, Alarcón V, Kindahl $\mathrm{H}$ and Edqvist L-E (1988) Levels of 15-keto-13,14-dihydro-PGF2 $\propto$ (progesterone and oestradiol-17 $\beta$, after induced ovulations in llamas and alpacas Acia Veterinarin Scandinavica $29339-346$

Sumar J, Edqvist L-E, Kindahl H, Fredriksson G and Alarcón V (1990) Niveles de Sulfato de Estrona periférica durante la gestación y puerperio en la alpaca y llama. In X Congreso Nacional de Ciencias Veterinarias. Cusco

Sumar J, Alarcón V and Echevarría L (1993) Niveles de progesterona periférica en alpacas y llamas y su aplicación en el diagnóstico precoz de gestación y otros usos clínicos Acta Andina 2 161-167

Wiepz DW and Chapman RJ (1985) Non-surgical embryo transfer and live birth in a llama Theriogenology 24 251-257 